\title{
Metabolic Changes in the Blood of Dromedary Camel at Early Post-partum
}

\author{
M. A. M. M. Shehab-El-Deen ${ }^{1,2}$, S. N. Al-Dobaib ${ }^{1} \&$ K. A. Al-Sobayil ${ }^{1}$ \\ ${ }^{1}$ Department of Animal Production and Breeding, College of Agriculture and Veterinary Medicine, Qassim \\ University, Buraidah, Saudi Arabia \\ ${ }^{2}$ Department of Animal Production, Faculty of Agriculture, Suez Canal University, Ismailia, Egypt \\ Correspondence: M. A. M. M. Shehab-El-Deen, Department of Animal Production and Breeding, College of \\ Agriculture and Veterinary Medicine, Qassim University, 51452 Buraidah, Saudi Arabia. Tel: 966-56-412-6411. \\ E-mail: m.shehabeldeen@qu.edu.sa
}

Received: September 14, 2019

Accepted: October 24, 2019

Online Published: December 15, 2019

doi:10.5539/jas.v12n1p21

URL: https://doi.org/10.5539/jas.v12n1p21

The research is financed by National Science, Technology and Innovation Plan (MAARIFAH) (Project no. 12-AGR3207-09), King Abdulaziz City for Science and Technology, Kingdom of Saudi Arabia.

\begin{abstract}
Postpartum resumption of ovarian activity under environmental stressors is highly important for determining subsequent fertility in camel. The current study aimed to investigate the relationship of relevant biochemical and hormonal parameters in the blood serum with regard to ovarian resumption of dromedary camel at early post-partum. Blood samples were collected from female dromedary camel weekly during the postpartum period for 9 successive weeks. Serum and plasma samples were assayed for the following biochemical and hormonal constituents, glucose, cholesterol (CH), triglycerides (TG), total protein (TP), urea, insulin-like growth factor-1 (IGF-1), non-esterified fatty acids (NEFA), lactate dehydrogenase (LDH), cortisol and triiodothyronine (T3). Glucose concentrations ranged between 92.6 and $96.2 \mathrm{mg} / \mathrm{dL}$ for the first 6 weeks postpartum, and increased to $106.8 \mathrm{mg} / \mathrm{dL}$ at week 7 postpartum $(\mathrm{P}<0.01)$. The concentrations of $\mathrm{CH}$ followed almost the same manner during the first 7 weeks (ranged between 27.5 and $30.4 \mathrm{mg} / \mathrm{dL}$ ) and increased to $38.2 \mathrm{mg} / \mathrm{dL}$ at week 8 postpartum $(\mathrm{P}<0.01)$. Likewise, total protein concentrations decreased from $6.86 \mathrm{~g} / \mathrm{dL}$ week2 to $6.45 \mathrm{~g} / \mathrm{dL}$ at week 3 ( $\mathrm{P}<0.01)$ with no significant changes thereafter. Similarly, triglycerides decreased from $24.5 \mathrm{mg} / \mathrm{dL}$ at week 2 to $13.00 \mathrm{mg} / \mathrm{dL}$ at week $3(\mathrm{P}<0.01)$ with no significant changes up to week 9 . The concentrations of NEFA decreased significantly at week 3 postpartum $(\mathrm{P}<0.01)$ and then maintained at low level throughout the study period. Similarly, cortisol and IGF-1 concentrations were the lowest at week 3 postpartum $(5.7 \mu \mathrm{g} / \mathrm{dL}$ and $93.7 \mu \mathrm{g} / \mathrm{mL}$ for cortisol and IGF-1, respectively, $\mathrm{P}<0.01$ ) and then increased gradually with some little variations of IGF-1. However, the levels of urea followed a characteristic increasing and subsequently decreasing patterns while reached a plateau at weeks 8 and 9 postpartum. Similarly, the concentrations of T3 followed the same pattern and tended to increase at week 9 postpartum. Concentrations of LDH showed a significant decrease at weeks 4 to 6 postpartum and increased thereafter $(\mathrm{P}<0.01)$. Throughout the study period, changes of glucose, cortisol, CH, TP, IGF-1, NEFA and LDH had a clear trend, i.e. decreasing at early postpartum period followed by increasing patterns thereafter. The results of the present study suggest that the typical metabolic patterns that are found in blood serum of dromedary camel at postpartum may be reflected in the follicular fluid and, therefore, may use as an indication of reproductive resumption.
\end{abstract}

Keywords: blood metabolites, hormones, dromedary camel, fertility, postpartum

\section{Introduction}

In dairy cattle, postpartum negative energy balance (NEB) is directly related to reduced fertility (Beam \& Buttler, 1999; Lucy, 2008). Additionally, heat stress provokes NEB by reducing appetite, widening the energy gap between intake and expenditure through maintenance and milk production (Shehab-El-Deen et al., 2010). In camel, postpartum NEB is also found to be associated with delaying in uterine involution, resulting in delaying onset of postpartum ovarian cyclicity (Derar et al., 2014). In this regard, Merkt et al. (1990) reported that 
follicles in the ovaries could develop late in the gestation period, and this could be the reason for the signs of estrus observed early post-partum in camels. Although the literature on post-partum ovarian activities in camel is very limited, some studies reported that the post-partum estrus has been happened between 14 to 42 days following parturition (Elias et al., 1984). However, some research work has reported that the first post-partum estrus was delayed until the next breeding season (Musa \& Makawi, 1984). Therefore, it is speculated that the variation in post-partum estrus related to follicular development will be reflected in the biochemical components of the blood serum in camel since the changes in blood metabolites were related to developmental competence of oocytes in dairy cows (Leroy et al., 2004; Shehab-El-Deen et al., 2010).

The biochemical profiles of blood serum have widely been used to assess problems associated with the health status of animals (Lee et al., 1978; Hagawane et al., 2002). The assessment of blood biochemical profile is also used to investigate a lot of patho-physiological and metabolic disorders in animals (McDowell, 2003). For instance, a significantly higher levels of serum protein was detected in cyclic cows than in non-cyclic cows (El-Azab et al., 1993). Similarly, Burle et al. (1995) also reported low concentrations of serum cholesterol in anoestrus cows than in cycling cows. It is well-known that the developmental competence of the follicular growth is retarded and requires more time to become dominant follicle for ovulation under NEB conditions (Beam \& Buttler, 1998, 1999). If NEB is accompanied with heat stress the developmental competence of the dominant follicle is more adversely affected (Shehab-El-Deen et al., 2010; Ferreira et al., 2011). It is not known yet however, whether these NEB-heat stress associated changes present in the blood metabolites at post-partum are reflected in the reproductive cyclicity in camel. A comprehensive understanding on post-partum biochemical indices is needed for further improvement of camel reproduction. Therefore, the aim of this study was to investigate the relationship of relevant biochemical and hormonal parameters in the blood serum with regard to ovarian resumption of dromedary camel at early post-partum.

\section{Materials and Methods}

\subsection{Animals and Sample Preparation}

Ten post-partum she camel (dromedary), aged 10-12 years were used for this study. The animals had no history of dystocia or birth related problem during parturition. Blood samples were taken into three tubes (unheparinized, gel-clot activator tube; EDTA tube; sodium fluoride (NaF) tube) (Xinle Medical ${ }^{\circledR}, \mathrm{KSA}$ ) in each week up to 9 weeks post-partum. Blood samples were cooled at $4{ }^{\circ} \mathrm{C}$, and transported on ice $\left(4{ }^{\circ} \mathrm{C}\right)$ to the laboratory. The blood samples were centrifuged $(1400 \times g, 30 \mathrm{~min})$ within $2 \mathrm{~h}$ after collection and the serum or plasma was separated.

\subsection{Biochemical Analyses}

In each sample, the concentrations of triiodothyronine (T3), cortisol, glucose, cholesterol, triglycerides, urea, total protein, LDH, IGF1 and NEFA were measured. All analyses were performed at the Department of Animal Production and Breeding, College of Agriculture and Veterinary Medicine, Qassim University, Saudi. The metabolite levels in blood serum were done using Autoanalyser (random-access analyzer; Humastar 100). All measurements were carried out according to the manufacturers' instructions. Triiodothyronine (T3), cortisol (Human Diagnostics, KSA) and IGF1 (BioSource Europe S.A.) hormones were measured using specific enzyme-linked immunosorbent assay (ELISA) kits. The measurement was carried out according to the manufacturer's instructions.

\subsection{Statistical Analysis}

Results are expressed as means \pm S.E.M. The overall mean concentration \pm S.E.M. of each metabolite was calculated for blood in all she camel. The concentrations of each metabolite in the blood compared among 9 weeks postpartum.

Hypothesis testing was performed with the MIXED procedure of JMP (2013), using a model with repeated measures (time postpartum) with animals as a random effect. Two random errors were defined: 1) the variance between animals (subjects) within time postpartum; 2) the variance between measurements within animals (residual). The second random error was used to test the effects of time postpartum in the model. A value of $P<$ 0.05 was considered statistically significant.

\section{Results}

The results of different metabolites and hormones during postpartum period from first week of parturition until $9^{\text {th }}$ week are shown in Figures 1, 2, 3, 4, 5, 6, 7, 8, 9 and 10. The glucose concentrations stayed relatively stable $(93-96 \mathrm{mg} / \mathrm{dL})$ until 6 weeks post-partum followed by a sharp increase $(107 \mathrm{mg} / \mathrm{dL})$ at week 7 postpartum and then again maintained at steady levels $(105 \mathrm{mg} / \mathrm{dL})$ during the study period $(\mathrm{P}<0.01)$. Cholesterol followed the 
same pattern as of glucose levels except the relatively steady levels $(28-30 \mathrm{mg} / \mathrm{dL})$ maintained up to 7 weeks post-partum. Followed by a significant increase $(38.2 \mathrm{mg} / \mathrm{dL}$ and $36.6 \mathrm{mg} / \mathrm{dL})$ at weeks 8 and 9 post-partum, respectively. The serum concentration of triglycerides dropped significantly at week 3 postpartum and remained low up to week $9(\mathrm{P}<0.01)$. NEFA also followed the same pattern as of triglycerides while its concentration during first 2 weeks was around $0.27 \mathrm{mmol} / \mathrm{L}$ and later come about $0.15 \mathrm{mmol} / \mathrm{L}(\mathrm{P}<0.01)$. Urea concentrations in serum followed a characteristic pattern where the urea levels dropped at 2 weeks followed by increased and subsequently decreased until 7 weeks and significantly increased at week 8 postpartum $(\mathrm{P}<0.01)$. There was a marked decrease in total protein from week 3 postpartum followed by gradual decrease up to 6 weeks and then again gradual increase at week 9 postpartum $(\mathrm{P}<0.01)$. LDH followed almost the similar trend that observed in case of total protein where marked decreased was noticed at 4 weeks post-partum and gradual increase thereafter $(\mathrm{P}<0.01)$. The concentration of IGF-1 also followed a trend of LDH while a marked declined was evident at week 3 postpartum followed by gradual increase which reached at peak at week 7 post-partum $(\mathrm{P}<0.01)$. The level of cortisol dropped from week 2 followed by gradual increase throughout the study period $(\mathrm{P}<0.01)$. Triiodothyronine (T3) concentrations in blood serum insignificantly decreased from week 2 postpartum, remained almost steady levels until 6 weeks, and tended to increase throughout the study period up to 9 weeks.

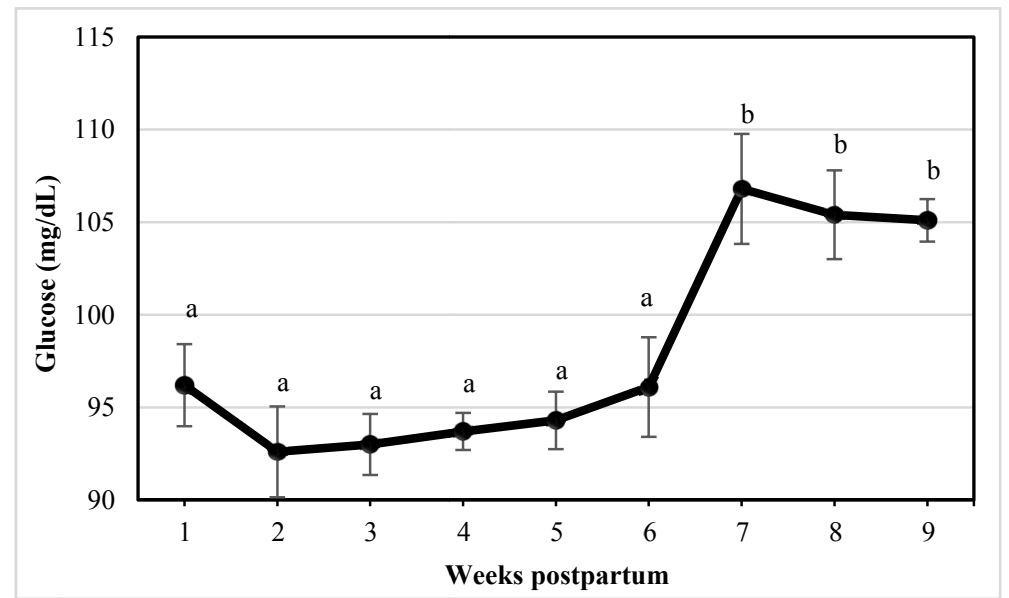

Figure 1. Concentrations of glucose $(\mathrm{mg} / \mathrm{dL})$ in blood serum during the postpartum period in female dromedary camel $(\mathrm{P}<0.01)$

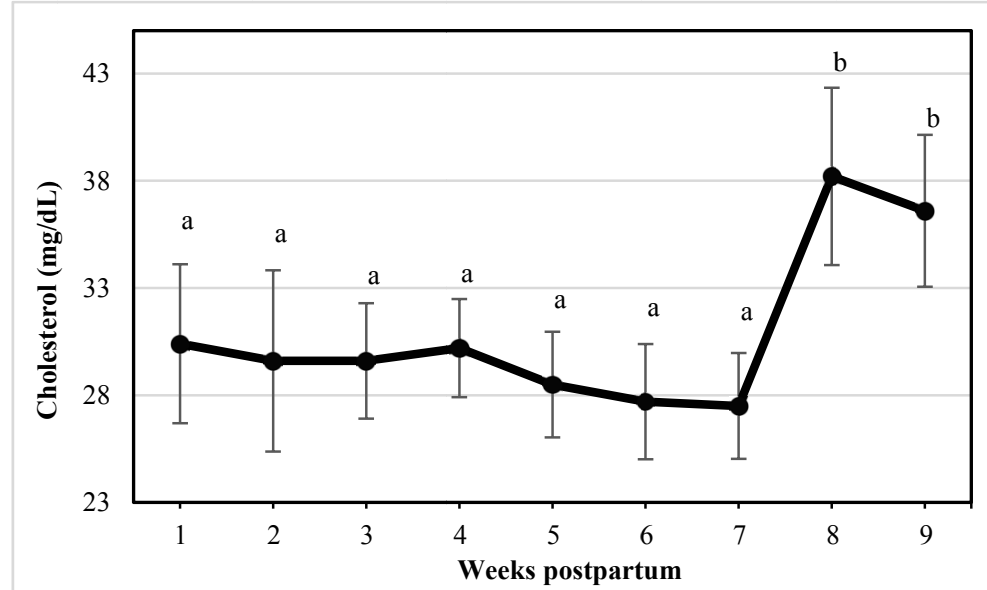

Figure 2. Concentrations of cholesterol $(\mathrm{mg} / \mathrm{dL})$ in blood serum during the postpartum period in female dromedary camel $(\mathrm{P}<0.01)$ 


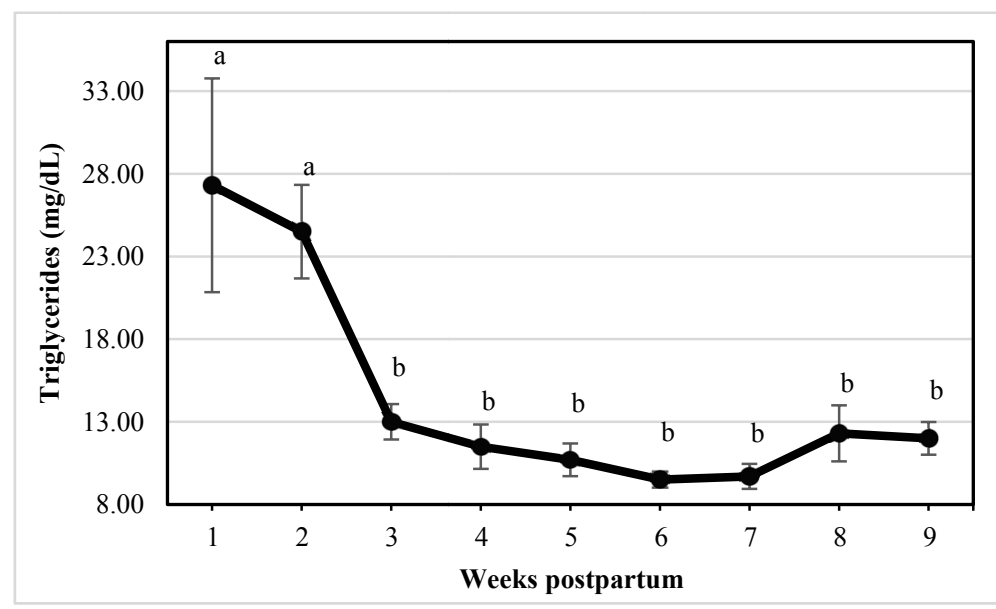

Figure 3. Concentrations of triglycerides $(\mathrm{mg} / \mathrm{dL}$ in blood serum during the postpartum period in female dromedary camel $(\mathrm{P}<0.01)$

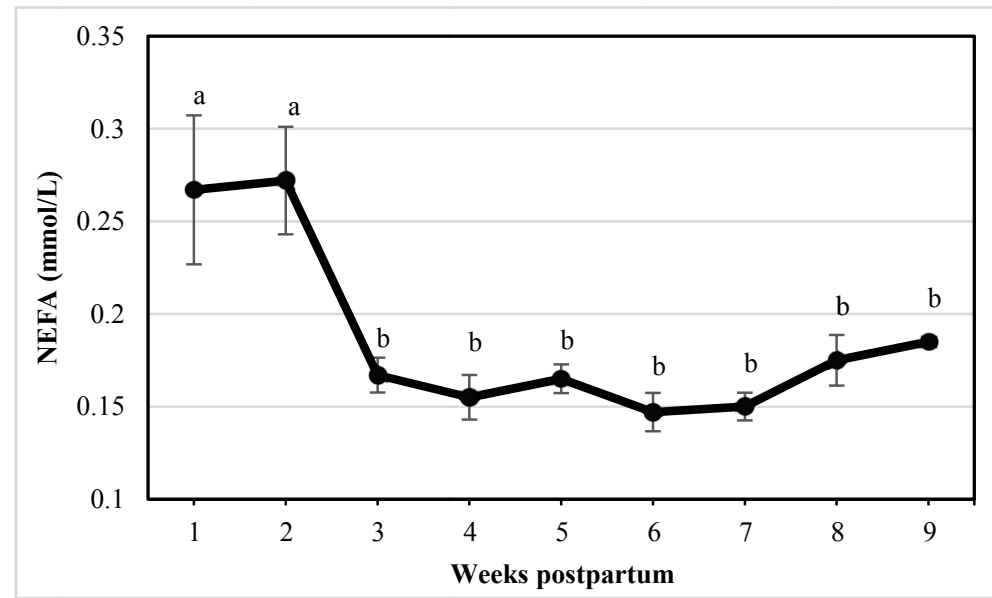

Figure 4. Concentrations of NEFAs ( $\mathrm{mmol} / \mathrm{L})$ in blood serum during the postpartum period in female dromedary camel $(\mathrm{P}<0.01)$

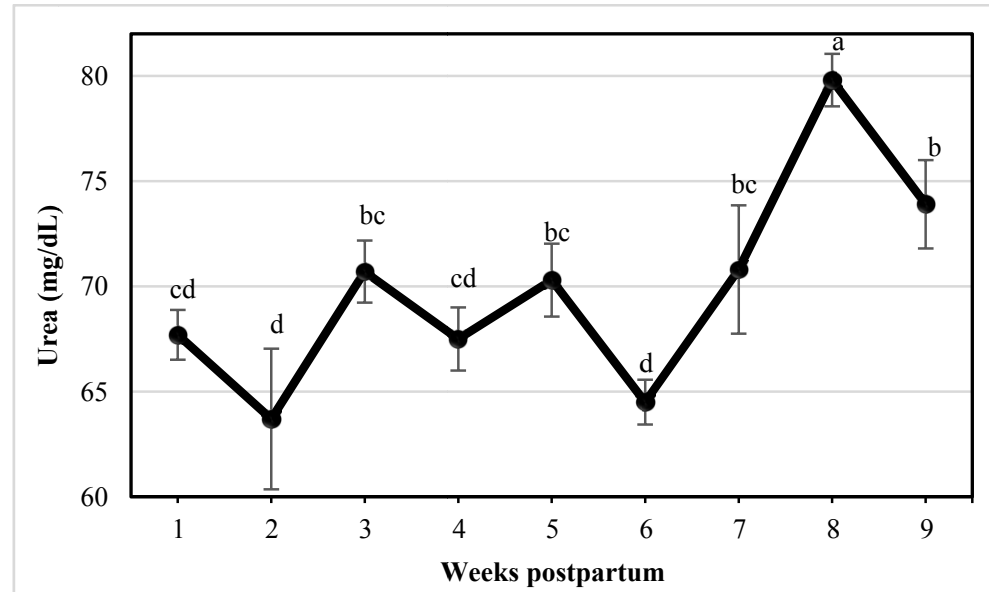

Figure 5. Concentrations of urea $(\mathrm{mg} / \mathrm{dL})$ in blood serum during the postpartum period in female dromedary camel $(\mathrm{P}<0.01)$ 


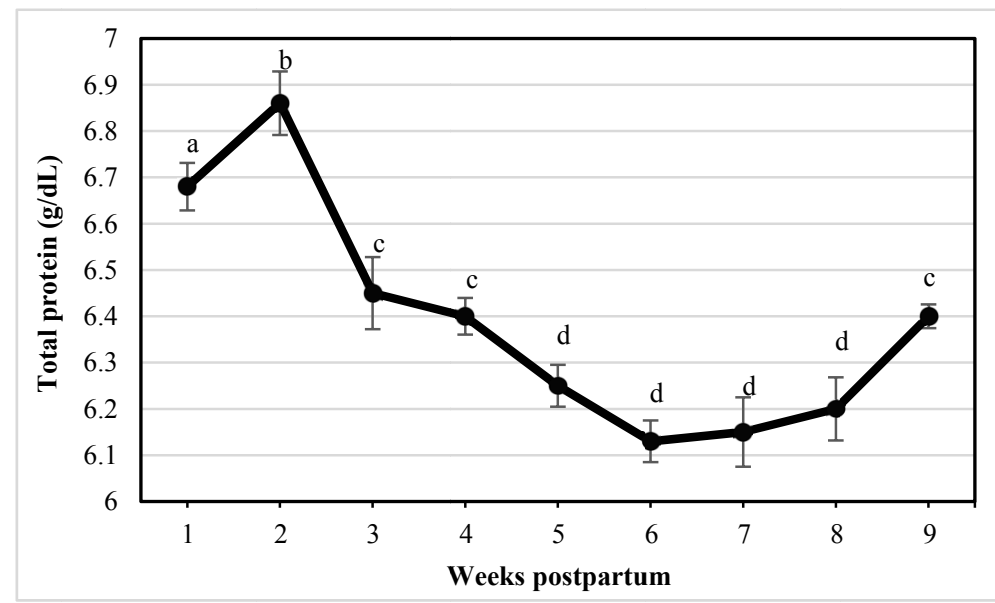

Figure 6. Concentrations of total protein $(\mathrm{g} / \mathrm{dL})$ in blood serum during the postpartum period in female dromedary camel $(\mathrm{P}<0.01)$

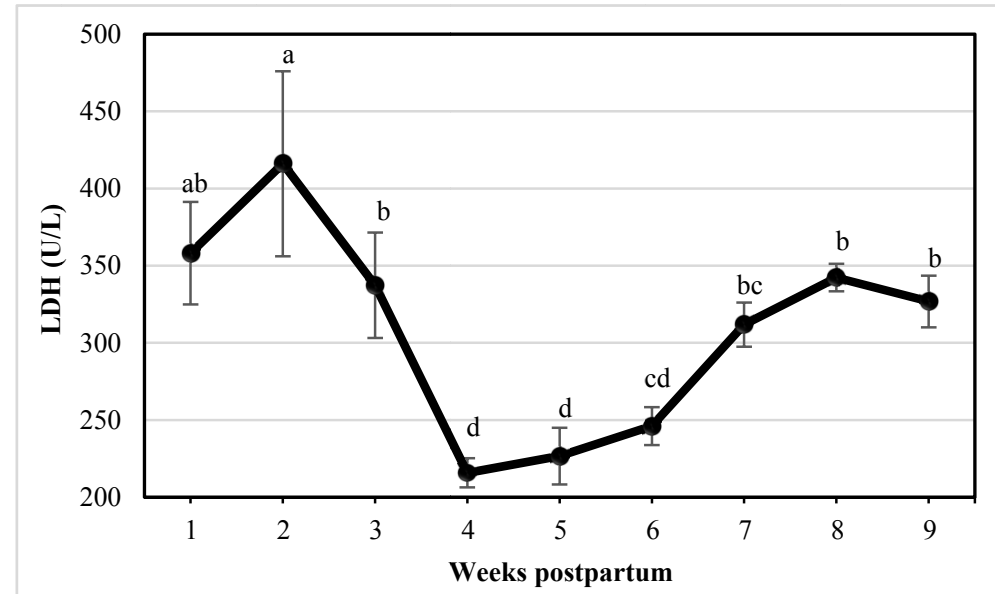

Figure 7. Concentrations of lactate dehydrogenase $(\mathrm{LDH} ; \mathrm{U} / \mathrm{L})$ in blood serum during the postpartum period in female dromedary camel $(\mathrm{P}<0.01)$

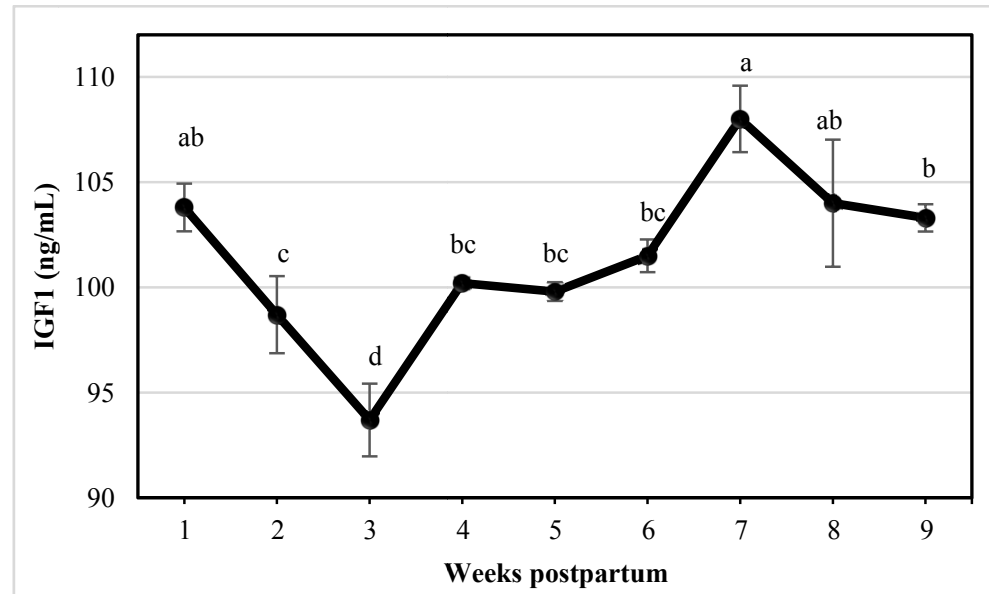

Figure 8. Concentrations of IGF-1 $(\mathrm{ng} / \mathrm{mL})$ in blood serum during the postpartum period in female dromedary camel $(\mathrm{P}<0.01)$ 


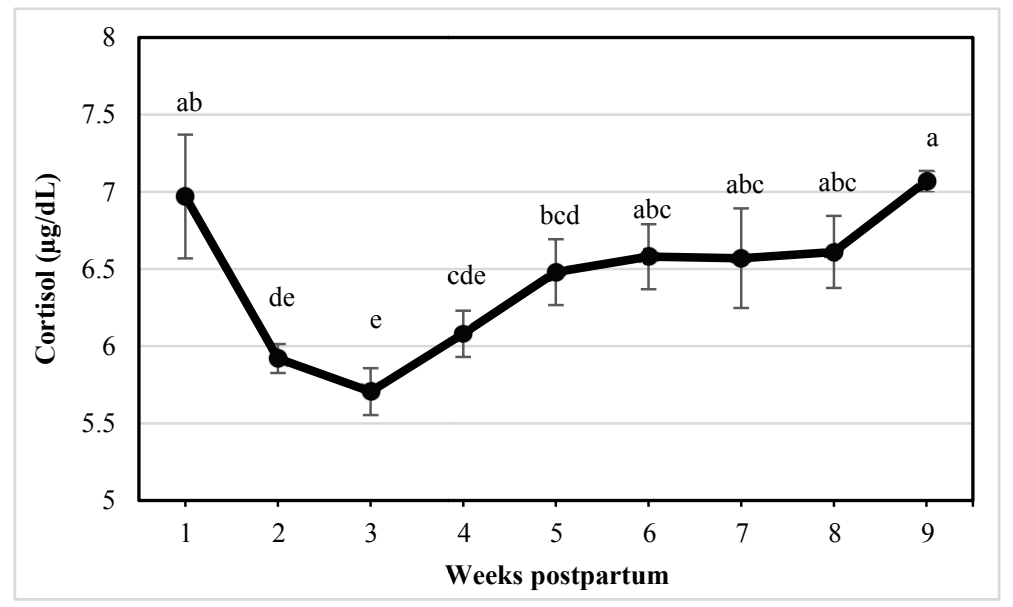

Figure 9. Concentrations of cortisol $(\mu \mathrm{g} / \mathrm{dL})$ in blood during the postpartum period in female dromedary camel $(\mathrm{P}<0.01)$

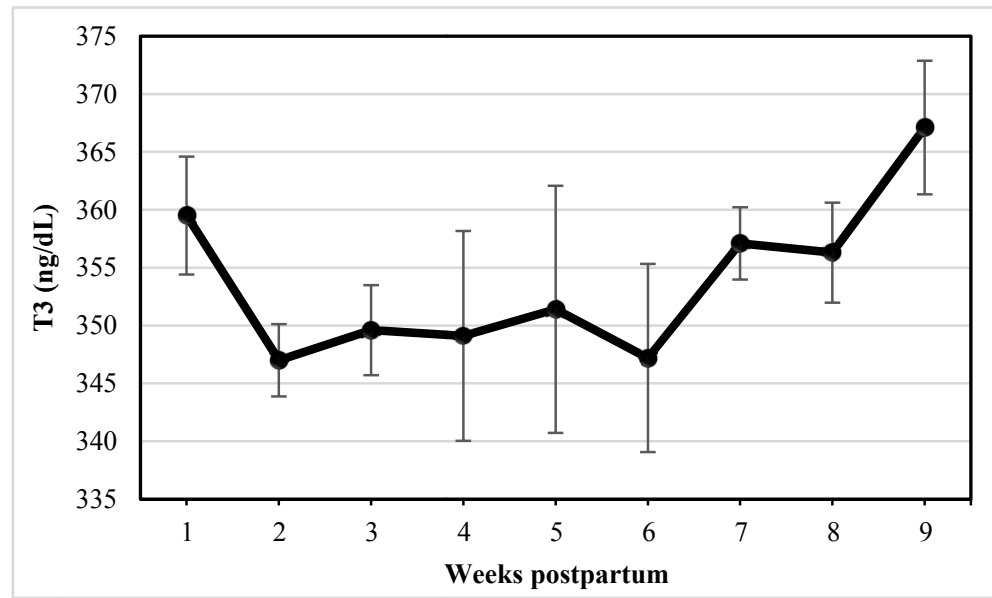

Figure 10. Concentrations of Triiodothyronine (T3; ng/dL) in blood serum during the postpartum period in female dromedary camel. (No significant effect of time postpartum were found)

\section{Discussion}

Blood metabolites are considered to be the major sources of follicular fluid components required for follicular growth and development which may determine the post-partum ovarian cyclicity. To the best of our knowledge, this is the first study where biochemical changes in blood serum are used as an indirect indication of ovarian resumption at early post-partum in camel.

The concentration of glucose in the blood serum showed a slight decrease at first 2 weeks post-partum followed by a gradual increase up to 6 weeks. Importantly, there is a sharp increase in glucose level at 7 weeks post-partum followed by no significant decrease or increase the period thereafter. In high yielding dairy cows, it is well-known that the glucose concentrations in blood serum are decreased during the period of negative energy balance and this low concentration of glucose in serum is closely related with follicular glucose levels (Butler, 2000; Leroy et al., 2004). While the NEB is associated with heat stress, the level of glucose declined very steadily (Shehab-El-Deen et al., 2010). In our study, we also observed glucose concentrations at basal level until 6 weeks post-partum followed a sharp increase, possibly indicating resumption of ovarian cyclicity.

Urea concentrations were relatively high and showed a characteristic decrease followed by increase pattern in the subsequent weeks until 7 weeks post-partum. However, at week 8 the pattern has been changed and urea concentrations increased exponentially followed by decreased significantly although still at high level. A very high concentrations of urea in blood serum or in follicular fluid was observed in mares and cattle's during early postpartum period (Kenny et al., 2002; Vanholder et al., 2005). A lot of studies concluded that the diet is responsible for elevated levels of urea and has a possible adverse effect on granulosa cells and oocyte 
competence (De Wit et al., 2001; Dawuda et al., 2002). Our results also indicate that elevated serum urea levels may be reflected in the follicular fluid of the dominant follicle and hence, may have adverse effect on granulosa cells and oocyte quality.

The level of total protein (TP) in the blood serum increased at 2 weeks post-partum possibly due to supply of higher amount of TP content following parturition. Afterwards the gradual decrease in TP in the succeeding weeks is possibly due to the effect of maintenance and milk production (Shehab-El-Deen et al., 2010). Our data contradicts with the finding in Holstein cows at early post-partum observed by Leroy et al. (2004) which may explain due to NEB associated with HS in camel. However, an increase in TP concentrations at 9 weeks post-partum is possibly an indication of resumption post-partum cyclicity which needs to be studied further at follicular fluid levels.

It is well-known that during the period of NEB, lipolysis causes an increase of NEFA concentrations in blood serum during the first week post-partum. This is in fact reflecting in our study where serum NEFA levels were relatively higher during the first 2 weeks post-partum. This finding supports the data of previous studies on cows subjected to an acute dietary restriction in order to mimic a period of NEB (Comin et al., 2002; Jorritsma et al., 2003). However, the sudden drops of NEFA levels at week 3 followed by maintaining almost a steady levels until the study period. It is anticipated that the lower levels of blood serum NEFA may be reflected the lower levels of NEFA in follicular fluid which is necessary to protect the oocyte and the granulosa cells from high NEFA concentrations since it is found toxic in culture condition in vitro (Yanase et al., 2001; Vanholder et al., 2005). The levels of triglycerides also follow almost the same pattern as of NEFA. This is probably because of elevation of very low-density lipoprotein (VLDL) triglycerides is closely related to elevation of NEFA in blood serum (Reaven \& Greenfeld, 1981; Yki-Jarvinen \& Taskinen, 1988).

Serum IGF-1 concentrations decreased very sharply during the first 3 weeks post-partum. A sharp decline in IGF-1 is directly related to the intense negative energy balance associated with heat stress (Shehab-El-Deen et al., 2010). Certain levels of IGF-1 in the follicular fluid are crucial for optimal follicular development (Beam \& Buttler, 1999) and oocyte quality (Adamiak et al., 2005). Both IGF-1 and glucose have beneficial effects on follicular growth, whereas, glucose is a primary source of energy for the ovary (Rabiee et al., 1997) and IGF-1 stimulates cell growth, cell development and differentiation (Jones \& Clemmons, 1995; Rosen \& Pollak, 1999). It has been well documented that the decrease in serum concentrations of glucose and IGF-1 in heat stressed cows is due to reduced dry matter intake (Abilay et al., 1975; De Rensis \& Scaramuzzi, 2003). The present study results support the findings of the above literature where we observed IGF-1 is markedly reduced during early 3 weeks post-partum followed by gradual increase that reached at plateau at 7 weeks, indicating the resumption of ovarian activities around 7 weeks post-partum along with the increasing concentrations of glucose.

The levels and role of lactate dehydrogenase (LDH), cortisol and triiodothyronine (T3) in post-partum were not studied before. In our previous study, we wanted to make a correlation of LHD concentration between follicular fluid and blood serum and observed significantly less concentration of LDH in follicular fluid, indicating the animals are free from diseases at least in part reproductive diseases (Shehab-El-Deen et al., 2019). A little decrease in LDH activity has also been reported in pregnant camels (Khadjeh, 2002; Saeed et al., 2009). In the present study, we observed a marked decrease in LDH levels at 4 weeks post-partum followed by gradual increase but less than periparturient levels, indicating the animals are approaching to reproductive soundness.

Cortisol elicits physiological adjustment that enables animal to tolerate stressful conditions. In agreement, we observed a sudden decline of cortisol at 3 weeks post-parturition followed by gradual increase in the subsequent weeks, indicating that the animals were in stress early post-partum that are recovered well at 9 weeks and thereafter. In an in vitro study, it has also found that the blastocysts developed from oocytes matured in cortisol-supplemented medium expressed relatively higher levels of glucose transporter 1 (GLUT1), fatty acid synthase (FASN), and heat shock protein 70 (HSP70) (Costa et al., 2016). This in vitro study elucidated a positive role of cortisol in the acquisition of bovine oocyte competence that is proved by increased embryonic development rates with elevated embryonic transcripts. Furthermore, cortisol has an important role in glucose and lipid metabolism, as well as the cellular reaction to stress. Although the role of Triiodothyronine (T3) in camel reproduction is very scares, the supplementation of $\mathrm{T} 3$ in bovine in vitro maturation medium has been found beneficial on the kinetics of embryo development (Costa et al., 2013). In a recent study, Singh et al. (2017) also reported that supplementation of T3 in bovine culture medium increased embryo cleavage rate. In our previous study, we observed significantly lower level of T3 in all follicle classes compared to blood serum. The present study also indicates that the level of cortisol was lower at 3 weeks post-partum followed by gradual increase in the weeks thereafter, indicating the possible resumption of ovarian cyclicity, which needs to be studied further. In conclusion, the results suggest that the glucose, cortisol, CH, TP, IGF-1 and NEFA patterns 
that are found in blood serum of dromedary camel at post-partum may be reflected in the follicular fluid and, therefore, may use as an indication of reproductive resumption.

\section{Acknowledgements}

This work was supported by National Science, Technology and Innovation Plan (MAARIFAH) (Project no. 12-AGR3207-09), King Abdulaziz City for Science and Technology, Kingdom of Saudi Arabia. The authors are also grateful to the Deanship of Scientific Research, Qassim University

\section{References}

Abilay, T. A., Johnson, H. D., \& Madan, L. M. (1975). Influence of environmental heat on peripheral plasma progesterone and cortisol during the bovine estrous cycle. J Dairy Sci, 58, 1836-1842. https://doi.org/ 10.3168/jds.S0022-0302(75)84795-3

Adamiak, S. J., Mackie, K., Watt, R. G., Webb, R., \& Sinclair, K. D. (2005). Impact of Nutrition on oocyte quality: Cumulative effects of body composition and diet leading to hyperinsulinemia in cattle. Biol Reprod, 73, 918-926. https://doi.org/10.1095/biolreprod.105.041483

Beam, S. W., \& Butler, W. R. (1998). Energy balance, metabolic hormones, and early postpartum follicular development in dairy cows fed prilled lipid. J Dairy Sci, 81, 121-131. https://doi.org/10.3168/jds.S00220302(98)75559-6

Beam, S. W., \& Butler, W. R. (1999). Effects of energy balance on follicular development and first ovulation in post partum dairy cows. J Reprod Fertil, 54, 411-424. https://doi.org/10.1530/biosciprocs.4.032

Blure, P. M., Mangle, N. S., Kothekhar, M. D., \& Kalorey, D. R. (1995). Blood biochemical profile during various reproductive states of Sahiwal and jersy X Sahiwal cattle. Livestock Adv, 20(7), 13-20.

Butler, W. R. (2000). Nutritional interactions with reproductive performance in dairy cattle. Anim Reprod Sci, 60/61, 449-457. https://doi.org/10.1016/S0378-4320(00)00076-2

Comin, A., Gerin, D., Cappa, A., Marchi, V., Renaville, R., \& Motta, M. (2002). The effect of an acute energy deficit on the hormone profile of dominant follicles in dairy cows. Theriogenology, 58, 899-910. https://doi.org/ 10.1016/s0093-691x(02)00922-6

Costa, N. N., Brito, K. N. L., Santana, P. P. S., Cordeiro, M. S., Silva, T. V. G., Santos, A. X., ... Ohashi, O. M. (2016). Effect of cortisol on bovine oocyte maturation and embryo development in vitro. Theriogenology, 85, 323-329. https://doi.org/10.1016/j.theriogenology.2015.08.010

Costa, N. N., Cordeiro, M. S., Silva, T. V. G., Sastre, D., Santana, P. P. B., Sá, A. L. A., .. Ohashi, O. M. (2013). Effect of triiodothyronine on developmental competence of bovine oocytes. Theriogenology, 80(4), $295-301$. https://doi.org/10.1016/j.theriogenology.2013.04.011

Dawuda, P. M., Scaramuzzi, R. J., Leese, H. J., Hall, C. J., Peters, A. R., \& Drew, S. B. (2002). Effect of timing of urea feeding on the yield and quality of embryos in lactating dairy cows. Theriogenology, 58, 1443-1455. https://doi.org/10.1016/s0093-691x(02)00973-1

De Rensis, F., \& Scaramuzzi, R. J. (2003). Heat stress and seasonal effects on reproduction in the dairy cow-a review. Theriogenology, 60, 1139-1151. https://doi.org/10.1016/s0093-691x(03)00126-2

De Wit, A. A. C., Cesar, M. L. F., \& Kruip, T. A. M. (2001). Effect of urea during in vitro maturation on nuclear maturation and embryo development of bovine cumulus-oocyte-complexes. J Dairy Sci, 84, 1800-1804. https://doi.org/10.3168/jds.S0022-0302(01)74618-8

Derar, R., Ali, A., \& Al-Sobayil, F. A. (2014). The postpartum period in dromedary camels: Uterine involution, ovarian activity, hormonal changes, and response to GnRH treatment. Anim Reprod Sci, 151, $186-93$. https://doi.org/10.1016/j.anireprosci.2014.10.024

El-Azab, M. A., Badr, A., El-Sadawy, H. A., Shawki, G., \& Borkat, T. M. (1993). Some biochemical changes in relation to postpartum ovarian activity in dairy cows. Indian J Anim Sci, 63(12), 1244-1247.

Elias, E., Bedrak, E., \& Yagil, R. (1984). Peripheral blood levels of progesterone in female camels during various reproductive stages. Gen Comp Endocrinol, 53, 235-240. https://doi.org/10.1016/0016-6480(84)90248-X

Ferreira, R. M., Ayres, H., Chiaratti, M. R., Ferraz, M. L., Araújo, A. B., Rodrigues, C. A., ... Baruselli, P. S. (2011). The low fertility of repeat-breeder cows during summer heat stress is related to a low oocyte competence to develop into blastocysts. J Dairy Sci, 94, 2383-2392. https://doi.org/10.3168/jds.2010-3904 
Hagawane, S. D., Shinde, S. B., \& Rajuru, S. B. (2002). Haematological and blood biochemical profile in lactating Buffaloes in and around Parbbani city. Vet World, 2(12), 467-469.

Jones, J. L., \& Clemmons, D. R. (1995). Insulin-like growth factors and their binding proteins: Biological actions. Endocr Rev, 16(1), 3-34. https://doi.org/10.1210/edrv-16-1-3

Jorritsma, R., Groot, M. W., Vos, P. L., Kruip, T. A., Wensing, T., \& Noordhuizen, J. P. (2003). Acute fasting in heifers as a model for assessing the relationship between plasma and follicular fluid NEFA concentrations. Theriogenology, 60, 151-161. https://doi.org/10.1016/s0093-691x(02)01358-4

Kenny, D. A., Humpherson, P. G., Leese, H. J., Morris, D. G., Tomos, A. D., \& Diskin, M. G. (2002). Effect of elevated systemic concentrations of ammonia and urea on the metabolite and ionic composition of oviductal fluid in cattle. Biol Reprod, 66, 1797-1804. https://doi.org/10.1095/biolreprod66.6.1797

Khadjeh, G. H. (2002). Concentration of serum enzymes in pregnant and non pregnant Iranian one-humped camels. Indian J Anim Sci, 72(5), 391-392.

Lee, A. J., Twardock, A. R., Bubar, R. H., Hall, J. E., \& Davis, C. L. (1978). Blood Metabolite profile: their use and relation to nutritional status of dairy cows. J Dairy Sci, 61, 1652-1670. https://doi.org/10.3168/ jds.S0022-0302(78)83780-1

Leroy, J. L. M. R., Vanholder, T., Delanghe, J. R., Opsomer, G., Van Soom, A., Bols, P. E. J., \& de Kruif, A. (2004). Metabolite and ionic composition of follicular fluid from different-sized follicles and their relationship to serum concentrations in dairy cows. Anim Reprod Sci, 80, 201-211. https://doi.org/10.1016/ S0378-4320(03)00173-8

Lucy, M. C. (2008). Functional differences in the growth hormone and insulin-like growth factor axis in cattle and pigs: implications for postpartum nutrition and reproduction. Reprod Domest Anim, 43(2), 31-39. https://doi.org/10.1111/j.1439-0531.2008.01140.x

McDowell, L. R. (2003). Mineral in animal and human nutrition (2nd ed.). Elsevier Imprint. Retrieved from https:/www.elsevier.com/books/minerals-in-animal-and-human-nutrition/mcdowell/978-0-444-51367-0

Merkt, H., Rath, D., Musa, B., \& El-Nagger, M. A. (1990). Reproduction in camels: A review (No. 23, pp. 1-51). Food and Agriculture Organization of the United Nations (FAO), Rome.

Mu, Y. M., Yanase, T., Nishi, Y., Tanaka, A., Saito, M., Jin, C. H., .. Nawata, H. (2001). Saturated FFAs, palmitic acid and stearic acid, induce apoptosis in human granulosa cells. Endocrinology, 142, 3590-3597. https://doi.org/10.1210/endo.142.8.8293

Musa, B. E., \& Makawi, S. (1985). Involution of the uterus and the first post-partum heat in the camel (Camelus dromedarius). Conf. Anim. Prod. in Arid Zones, Damascus.

Rabiee, A. R., Lean, I. J., Gooden, J. M., Miller, B. G., \& Scaramuzzi, R. J. (1997). An evaluation of transovarian uptake of metabolites using arterio-venous difference methods in dairy cattle. Anim Reprod Sci, 48, 9-25. https://doi.org/10.1016/S0378-4320(97)00032-8

Reaven, G. M., \& Greenfeld, M. S. (1981). Diabetic hypertriglyceridemia: Evidence for three clinical syndromes. Diabetes, 30(Suppl. 2), 66-75. https://doi.org/10.2337/diab.30.2.s66

Rosen, C. J., \& Pollak, M. (1999). Circulating IGF-1. New perspectives for a new century. Trends Endocrinol Metab, 10, 136-141. https://doi.org/10.1016/S1043-2760(98)00126-X

Saeed, A., Khan, I. A. \& Hussein, M. M. (2009). Change in biochemical profile of pregnant camels (Camelus dromedarius) at term. Comp Clin Path, 18, 139-143. https://doi.org/10.1007/s00580-008-0763-X

Shehab-El-Deen, M. A. M. M., Al-Dobaib, S. N., \& Al-Sobayil, K. A. (2019). Biochemical Compositions in the Follicular Fluid of Different Follicle Groups and Their Relationship with the Blood Concentrations in Dromedary Camels. International Journal of Biology, 11(4), 112-122. https://doi.org/10.5539/ijb.v11n4p112

Shehab-El-Deen, M. A. M. M., Leroy, J. L. M. R., Fadel, M. S., Saleh, S. Y. A., Maes, D., \& Van Soom, A. (2010). Biochemical changes in the follicular fluid of the dominant follicle of high producing dairy cows exposed to heat stress early post-partum. Anim Reprod Sci, 117, 189-200. https://doi.org/10.1016/ j.anireprosci.2009.04.013

Singh, A. K., Prakash, C., Rohit, K., Karunakaran, M., Santra, A., \& Das, S. K. (2017). In vitro development of cattle embryos using triiodothyronine as a media supplement. Int J Adv Biotech Res, 7, 25-31. 
Vanholder, T., Leroy, J. L., Van Soom, A., Opsomer, G., Maes, D., Coryn, M., \& de Kruif, A. (2005). Effect of non-esterified fatty acids on bovine granulosa cell steroidogenesis and proliferation in vitro. Anim Reprod Sci, 87(1-2), 33-44. https://doi.org/10.1016/j.anireprosci.2004.09.006

Yki-Jarvinen, H., \& Taskinen, M. R. (1988). Interrelationships among insulin's antilipolytic and glucoregulatory effects and plasma triglycerides in nondiabetic and diabetic patients with endogenous hypertriglyceridemia. Diabetes, 37, 1271-1278. https://doi.org/10.2337/diab.37.9.1271

\section{Copyrights}

Copyright for this article is retained by the author(s), with first publication rights granted to the journal.

This is an open-access article distributed under the terms and conditions of the Creative Commons Attribution license (http://creativecommons.org/licenses/by/4.0/). 